\section{Sistem Sambungan Struktur dalam Rumah Panggung}

\section{Widija Suseno Widjaja ${ }^{1}$ Etty Endang Listiati ${ }^{2}$ IM. Tri Hesti Mulyani ${ }^{2}$ Bernadette Tyas Susanti ${ }^{2}$}

${ }^{1}$ Dosen Teknik Sipil Universitas Katolik Soegijapranata, Semarang.

${ }^{2}$ Dosen Arsitektur Universitas Katolik Soegijapranata, Semarang.

widija@unika.ac.id
Rumah panggung sering dijumpai di daerah banjir atau rob yaitu naikknya permukaan air laut di daerah permukaan dekat pantai. Rumah panggung dibangun dengan harapan pemilik tidak perlu mengurug lantai rumahnya secara berkala. Rumah panggung harus direncanakan dengan kokoh kekuatannya mulai dari struktur bawah sampai struktur atas. Pondasi rumah panggung yang terletak di atas tanah rob sering mempunyai daya dukung yang rendah karena berupa tanah rawa-rawa berlumpur. Agar rumah panggung dapat berdiri lebih tinggi, maka dipasang kolom pipa galvanis yang dapat diatur ketinggiannya dengan sistem hidrolis. Struktur rumah panggung direncanakan dengans struktur yang ringan yang menggunakan struktur bambu yang bertumpu pada kolom-kolom hidrolis. Material rumah panggung ada yang terbuat dari bambu, beton dan baja sehingga konstruksi sambungannya harus direncanakan dan diperhitungkan dengan baik. Sambungan yang akan dibahas adalah sambungan baja dengan beton pondasi dengan menggunakan base plate dan angkur baut. Sambungan pipa hidrolis, sambungan pipa galvanis dengan struktur bangunan bambu serta struktur rumah bambu.

Kata kunci: Sambungan Baja Beton, Base Plate, Angkur Baut, Sambungan Pipa-Bambu, Sambungan Batang-Batang Bambu.

Dipresentasikan: 30 Agustus 2019

Direvisi: 14 September 2019

Diterima: 9 Oktober 2019

Dipublikasikan online: 10 Oktober 2019

\section{Pendahuluan}

Rumah merupakan kebutuhan pokok manusia dalam beraktivitas sehari-harinya. Rumah di daerah pantai sering terdampak bencana rob, yaitu masuknya air laut ke daerah permukiman disekitar pantai. Dengan masuknya air laut ke pemukiman, membuat lingkungan menjadi kumuh, lantai rumah tergenang air yang akhirnya penghuni menjadi tidak nyaman dan menjadikan kurang sehat.

Pada umumnya, agar lantai rumah tidak tergenang air, secara berkala, penduduk menimbun tanah di dalam rumah agar tidak tergenang air. Penimbunan ini berakibat rumah di sekitarnya yang tidak ditimbun menjadi lebih parah, untuk itu perlu dibuat aturan atau ketentuan dari pemerintah daerah setempat untuk mengelola lingkungan diwilayah bencana rob, sehingga tidak menjadi lebih parah atau kumuh. Untuk mengantisipasi kondisi diatas perlu direncanakan bangunan yang dapat ramah lingkungan dan biaya yang tidak terlalu mahal serta dapat dimanfaatkan dalam jangka waktu yang cukup lama.

Karena kondisi tanah di daerah rob, selalu tergenang air dan umumnya berlumpur, menjadikan daya dukung tanah dalam mendukung beban di atasnya sangat rendah. Kondisi tanah di daerah rob, sangat bervariasi, terutama mengenai kedalaman tanah dan kemampuan daya dukungnya yang memungkinkan terjadinya penurunan pondasi yang berbeda.
Agar bangunan yang dibangun tidak cepat terkejar dengan kenaikan muka air rob, maka harus direncanakan ketinggian lantai bangunan yang dapat fleksibel dapat di naik turunkan secara berkala. Struktur bangunan diatasnya harus dibuat dari struktur yang ringan, agar pondasi yang dibuat tidak terlalu besar, karena kondisi daya dukung tanahnya yang rendah. Untuk semua perencanaan bangunan diatas dari bangunan pondasi sampai bangunan atasnya, harus dibuat yang kokoh dan awet serta dapat berfungsi cukup lama. Perencanaan tersebut jalan satusatunya yang pantas adalah perencanaan sambungan dari bagian struktur bangunan, sehingga bangunan tersebut menjadi kuat dan nyaman untuk ditempati.

Sambungan - sambungan yang perlu direncanakan dengan baik dan memenuhi persyaratan-persyaratan teknis /perencanaan struktur, meliputi sambungan kolom baja hidrolis dengan beton pondasi telapak dengan menggunakan base plate dan angkur baut, sambungan pipapipa hidrolis, sambungan pipa hidrolis dengan struktur bambu rumah panggung, struktur sambungan batangbatang bambu dari rumah panggung hidrolis.

\section{Metode}

Metode yang digunakan dalam penelitian ini adalah metode eksperimental di daerah rob yang lahannya di izinkan untuk dibangun rumah contoh

Cara mensitasi artikel ini:

Widjaja, W. S., Listiati, E. E., Mulyani, T. H., Susanti, B. T. (2019) Sistem Sambungan Struktur dalam Rumah Panggung. [Edisi Khusus]. Buletin Profesi Insinyur 2(3): 125-132 
Rumah contoh yang dibangun adalah rumah panggung yang diharapkan dapat berfungsi dan dapat bermanfaat dalam waktu-waktu mendatang oleh pemiliknya. Setelah diadakan survey di daerah pantai utara kota Semarang, didapatkan rumah di Kelurahan Kemijen, Kecamatan Semarang Utara, Kotamadya Semarang yang saat itu mengalami rob.

Lahan yang dimiliki Bapak Herianto akan didirikan rumah panggung dengan ukuran modul $3 \mathrm{~m} \times 3 \mathrm{~m}$, dan ketinggian lantai rumah 1,5 $\mathrm{m}$ dari balok sloof, yang dapat di naikkan hingga ketinggian 2 meter.

Dengan izin perangkat desa setempat, RT, RW, Kepala Kelurahan Kemijen, maka mulailah dibangun rumah panggung tersebut, dengan menggunakan dana penelitian Ristek Dikti (PPTU PT) dan Unika Soegijapranta dengan topik model desain rumah yang adaptif terhadap rob, Kelurahan Kemijen Semarang Tahun 2018.

\section{Hasil dan Analisis}

Hasil kerja yang telah diperoleh dari penelitian ini selesainya pembangunan rumah panggung yang dilaksanakan sekitar 1,5 sampai dengan 2 bulan.

Pembangunan Rumah Panggung dimulai dari pembersihan lahan lokasi rumah panggung, kemudian dilakukan uitzet (pengukuran batas dari ketinggian rencana pondasi) selanjutnya adalah melakukan pemancangan terucuk bambu sedalam $3 \mathrm{~m}$ dengan jumlah 9 batang bambu setiap pondasi telapak.

Kemudian pemasangan kolom - kolom hidrolis, yang terbuat dari pipa galvanis $\emptyset 3^{\prime \prime}$ dan $\emptyset 4 "$, dengan lubang lubang baut $\emptyset 19 \mathrm{~mm}$, dengan interval $25 \mathrm{~cm}$, sehingga dengan ketinggian awal $1,5 \mathrm{~m}$, besi di dongkrak menjadi 2 $\mathrm{m}$. Kolom - kolom hidrolis ini terdiri diatas kolom pondasi, dengan menggunakan base plate dan angkur baut seperti dalam buku perilaku, analisa dan design struktur baja dengan AISC 2010 (Dewobroto, 2015).

\section{Sambungan Baja Terhadap Beton}

Struktur baja umumnya digunakan untuk bangunan struktur atas, sedangkan di bagian bawah pondasi mengandalkan struktur beton, untuk menyambungkan keduanya perlu disiapkan sambungan yaitu base plate pada tumpuannya. Base plate dibuat untuk transfer gaya atau momen dari struktur baja yang relatif lebih kuat, ke struktur beton yang lebih lemah tanpa menimbulkan kerusakan. Konstruksi base plate biasanya terdiri dari pelat landasan yang dilas dengan profil kolomnya dan diperkuat dengan angkur baut.

Agar terjadi kontak yang merata antara pelat base plate (pelat landasan) dan struktur beton pondasi, diberi jarak dan diisi dengan semen grout tipe tidak susut (non shrink grout). Dibagian pinggir base plate dipasang minimal dua buah angkur, untuk mengantisipasi momen tidak terduga selama masa konstruksi fungsi baut angkur baja untuk leveling dan menahan gaya geser. Tebal base plate minimum $10 \mathrm{~mm}$. Detail base plate yang standar dapat dilihat dalam Gambar 1.

Untuk beban tekan konsentris seperti terlihat Gambar 2, jika dimensi base plate $B \times N$, maka daya dukung beton $f_{p}$, agar beton di bawahnya tidak rusak, harus memenuhi ketentuan berikut:

$$
f_{p}=\frac{P_{u}}{B \cdot N} \leq f_{p} \max
$$

dengan $f_{p \text { max }}=\emptyset_{c} \cdot 0,85 f_{c^{\prime}}$

Kuat perlu base plate

$$
M_{p l}=\frac{1}{2} \quad f_{p} L^{2}
$$

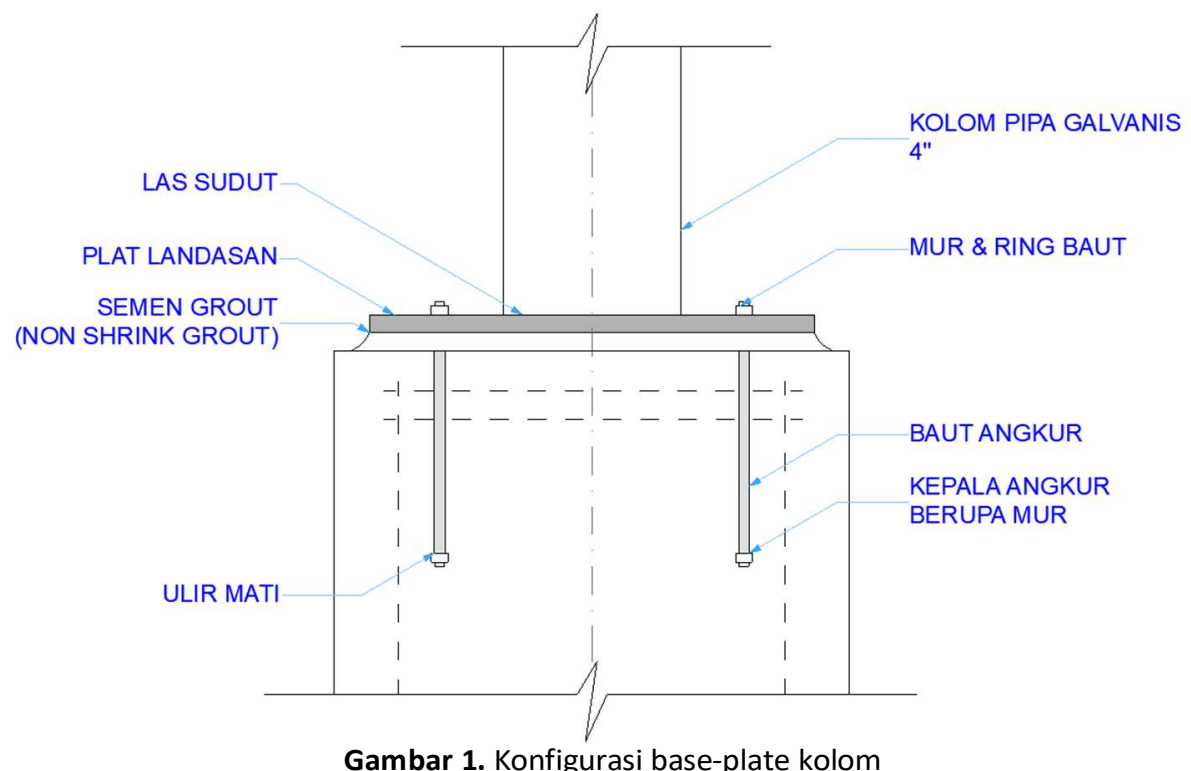




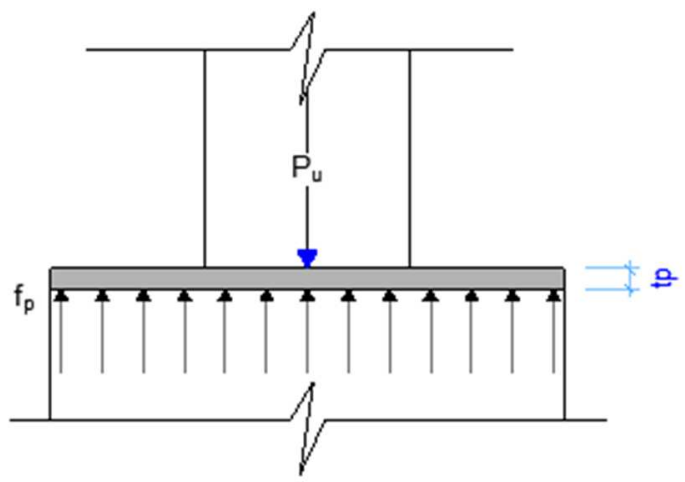

(a) Tegangan Tumpu Beton

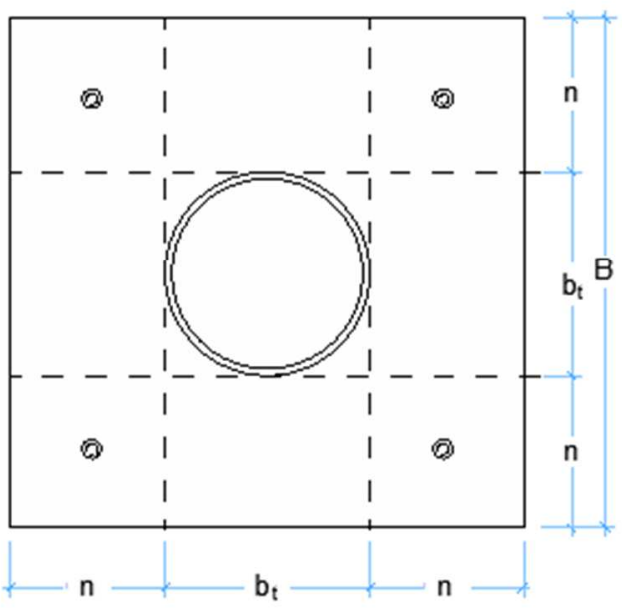

(b) Anggapan Garis Lentur Pelat

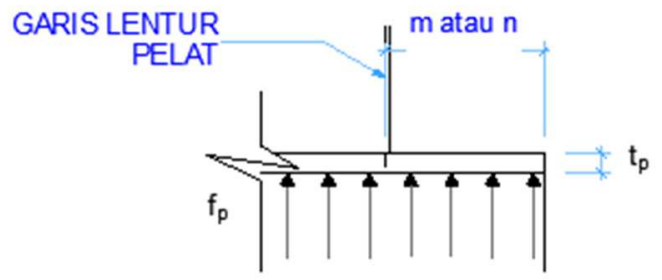

(c) Menentukan Momen Pelat

Gambar 2. Base plate terhadap beban tekan konsentris, digambar kembali berdasarkan Dewobroto (2002)

Dengan $L$ diambil dari nilai terbesar dani $m, n$ dan $\lambda_{n^{\prime}}$

$$
\begin{aligned}
& m=\frac{N-0,95 d}{2} \\
& n=\frac{B-0,8 b_{f}}{2} \\
& \lambda_{n^{\prime}}=\frac{1}{4} \lambda \sqrt{d \cdot b_{f}} \\
& \lambda=\frac{2 \sqrt{x}}{1+\sqrt{1-x}} \ll 1 \\
& \mathrm{x}=\left\{\frac{4 d \cdot b_{f}}{\left(d+b_{f}\right)^{2}}\right\} \frac{P_{u}}{\emptyset_{c} \cdot P_{p}}
\end{aligned}
$$

Tebal minimum base plate

$$
t_{p} \geq \sqrt{\frac{4 M P_{b}}{\emptyset F_{y}}}=l \sqrt{\frac{2 f_{p}}{\emptyset F_{y}}}=l \sqrt{\frac{2 P_{u}}{\emptyset F_{y} B N}}
$$

$$
\text { dengan } \varnothing=\text { faktor ketahanan terhadap lentur }(0,9)
$$$$
\mathrm{I}=\text { nilai minimum dari } \mathrm{m}, \mathrm{n} \text { dan } \lambda_{\mathrm{n}^{\prime}}
$$

Perhitungan Base Plate (Gambar 3) Rumah Panggung Ukuran $250 \mathrm{~mm}$ x $250 \mathrm{~mm}$

$$
\mathrm{f}_{p}=0,65 \cdot 0,85 \cdot 35=19,3 \mathrm{MPa} \quad f_{c^{\prime}}=35 \mathrm{MPa}
$$


$m=\frac{250-0,95 \cdot 101,6}{2}=173,26 \mathrm{~mm}$

$n=\frac{250-0,8 \cdot 101,6}{2}=165,64 \mathrm{~mm}$

$\emptyset_{c} \cdot P_{p}=\frac{0,65 \cdot 0,85 \cdot 35 \cdot 250 \cdot 250}{1000}=1 \cdot 208,59 \mathrm{kN}$

$X=\frac{4 \cdot 101,6 \cdot 101,6}{(101,6+101,6)^{2}} \frac{9000}{1208,59}=\frac{41 \cdot 290,24}{41,290,24} \cdot 7,446=7,45$

$\lambda=\frac{2 \sqrt{7,45}}{1+\sqrt{1-7,45}}=\frac{2 \cdot 2,73}{1+\sqrt{-6,45}}=\frac{5,46}{1-2,55}=-3,52 \leq 1$

(beban terlalu kecil, diambil $\lambda=1$ )

$\lambda \cdot n^{\prime} \cdot 2 \cdot \frac{1}{4} \cdot 1 \sqrt{101,6 \cdot 101,6}=25,4 \mathrm{~mm}$

$M_{p L}=\frac{1}{2} \cdot 0,144 \cdot 173,26^{2}=2 \cdot 161,36 \mathrm{Nmm} / \mathrm{mm}$

$t_{p}=\sqrt{\frac{4.2161,36}{0,9 \times 250}}=\sqrt{\frac{8645,44}{225}}=\sqrt{38,42}$ $=6,2 \mathrm{~mm} \sim 10 \mathrm{~mm}($ tebal minimal $)$

\section{Sambungan Kolom Hidrolis}

Perhitungan kolom pipa hidrolis (Gambar 4) meliputi kebutuhan baut tiap kolom hidrolis:

- Tahanan tumpu baut pendukung

$$
\begin{aligned}
\varnothing R_{n} & =0,75 \cdot\left(2,4 \cdot f u^{p}\right) \cdot d_{b} \cdot t_{p} \\
& =0,75 \cdot(2,4 \cdot 370) \cdot 19 \cdot 5 \\
& =63 \cdot 270 \mathrm{~N} / \text { baut } \\
& =6,327 \text { ton/baut }
\end{aligned}
$$

$f u^{p}=$ tegangan batas plat, $d^{b}=$ diameter baut, $t^{p}=$ tebal plat

- Tahanan geser baut dengan 2 bidang geser

$\varnothing R_{n}=0,75 \cdot\left(0,5 f u^{b}\right) \cdot m \cdot A b$

$=0,75 \cdot 0,5 \cdot 825 \cdot 2 \cdot 15,17$

$=93.864 \mathrm{~N} /$ baut

$=93,864$ ton $/$ baut

$f u^{p}=$ tegangan batas plat, $m=$ jumlah bidang geser,$A b=$ luas penampang baut

- Perhitungan jumlah baut $=(0,90442 / 4$ tiang $) / 6,327$ ton $=0,036$ baut

dipakai minimal 2 baut/tiang (Baut tipe $\mathrm{A} 325$ dengan diameter $19 \mathrm{~mm}$ )

- Keliling lingkaran pipa $4 "=2$. $\Pi \cdot R=2 \cdot 3,14 \cdot(1 / 2$. diameter 4")

$=2 \cdot 3,14 \cdot(1 / 2 \cdot 4 \cdot 2,54 \mathrm{~cm})$ $=31,90 \mathrm{~cm}$

- Panjang setengah lingkaran $\quad=15,95 \mathrm{~cm}$
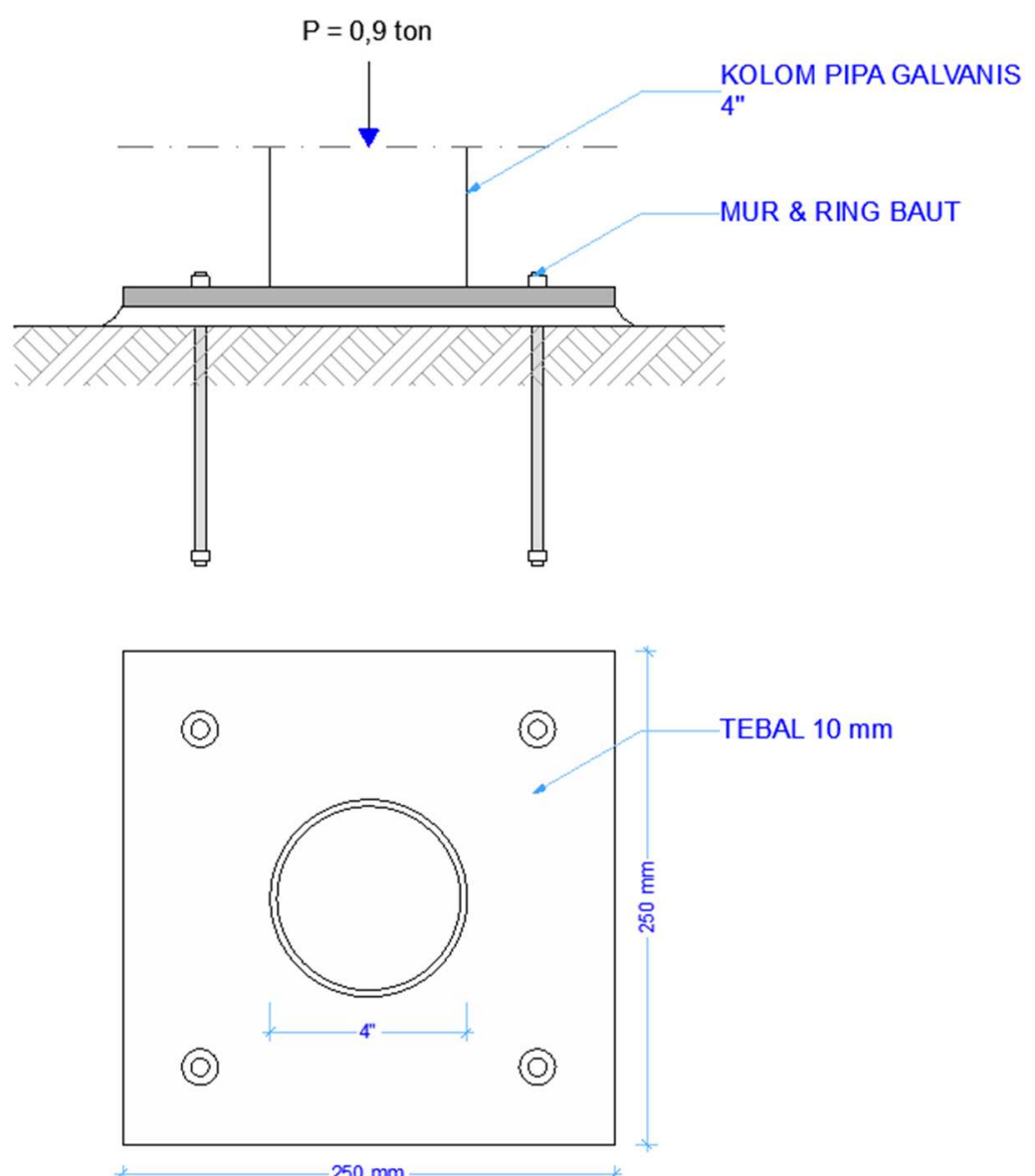

Gambar 3. Struktur base plate, digambar kembali berdasarkan Dewobroto (2002) 


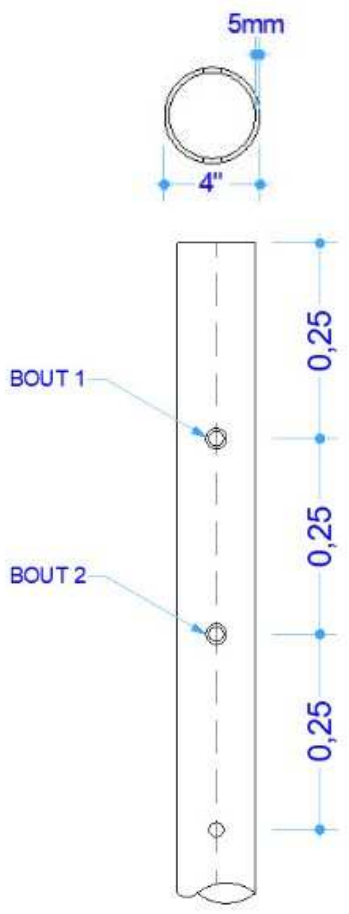

Gambar 4. Struktur pipa hidrolis

Pengecekan geser blok pada pipa $\varnothing 4^{\prime \prime}$

- $\mathrm{A}_{\mathrm{gv}}=500 .(5)$

$$
=2.500 \mathrm{~mm}^{2}
$$

- $\quad A_{n v}=\{500-1,5 .(19+2) .(5$ tebal $m m)\}$

$$
=2.342,5 \mathrm{~mm}^{2}
$$

- $\quad \mathrm{A}_{\mathrm{gt}}=159,5 \mathrm{~mm} .(5)$

$$
=797,5 \mathrm{~mm}^{2}
$$

- $\quad A_{n t}=\{159,5-0,5 \cdot(19+2) \cdot(5)\}$

$$
=745 \mathrm{~mm}^{2}
$$

$A_{g v}=$ luas penampang gross atau utuh untuk geser, $A_{n v}$ = luas penampang netto atau bersih untuk geser, $A_{\mathrm{gt}}=$ luas penampang gross untuk tarik, $A_{n t}=$ luas penampang netto untuk tarik

$$
\begin{aligned}
& \text { - } \mathrm{f}_{\mathrm{u}} \mathrm{A}_{\mathrm{nt}} \quad=370.745 \\
& =275.650 \mathrm{~N} \\
& \text { - } \quad 0,6 f_{u} \cdot A_{n v}=0,6 \cdot 370 \cdot 2342,5 \\
& =520.035 \mathrm{~N} \\
& \text { Karena fu. } A_{n t}<0,6 \text {. fu. } A_{n v} \text {, maka, } \\
& \mathrm{T}_{\mathrm{n}} \quad=0,6 \mathrm{fu} . A_{\mathrm{nv}}+\mathrm{fy} . \mathrm{A}_{\mathrm{gt}} \\
& =520 \cdot 0,35 \mathrm{~N}+275 \cdot 50 \mathrm{~N} \\
& =795.685 \mathrm{~N} \\
& =79,6 \text { ton } \\
& \varnothing T_{n} \quad=0,75 \text { (angka reduksi 0,75) . 79,6 ton } \\
& =59,625 \text { ton }>0,90442 \text { ton }
\end{aligned}
$$

Kemampuan pipa galvanis menahan beban sebesar 59,625 ton, padahal beban ada hanya 0,90442 ton. Pipa galvanis $\varnothing$ 4 ", aman terhadap geser balok.

\section{Sambungan Kolom Baja dan Struktur Bambu (Gambar 5)} Untuk sambungan ini dibuatkan pelat baja pemimpin struktur bambu dengan tebal $10 \mathrm{~mm}$. Pelat baja ini di las keliling dengan pipa hidrolis $\varnothing 3$ " dan di sisi atas pelat baja dipakai untuk tumpuan struktur bambu. Rumah panggung dengan diberikan penjepit atau pengaku strip plat ukuran 1 $1 / 2 " \times 5 \mathrm{~mm}$. Masing - masing segitiga strip plat diperkuat dengan baut $\varnothing 19 \mathrm{~mm}$ sebanyak 2 atau 3 baut setiap sisi seperti terlihat pada Gambar 2 . Segitiga strip plat ini di sisi bawah di las dengan pelat penyangga, tumpuan struktur bambu.

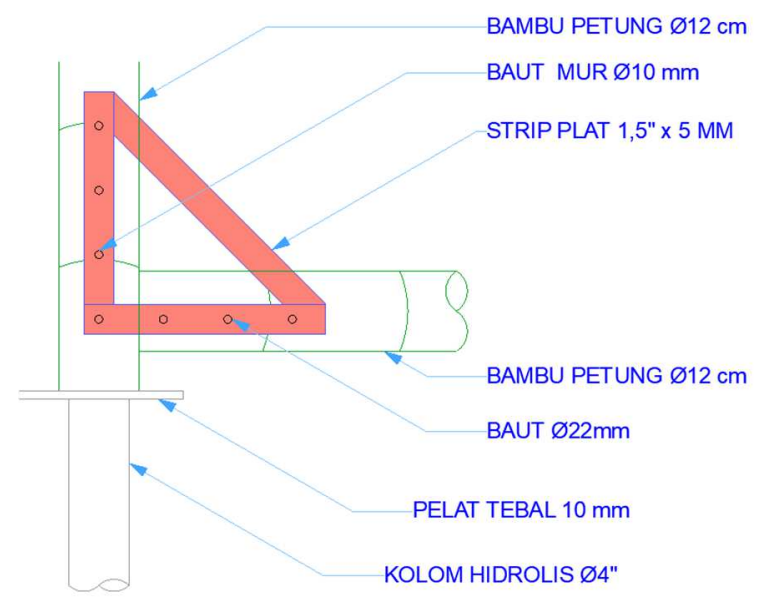

Gambar 5. Sambungan kolom baja dengan struktur bambu

\section{Sambungan Struktur Batang-Batang Bambu}

Batang-batang bambu yang berbentuk bulat pipa memanjang, ada teknik tersendiri untuk membuat sambungan bambu alat sambung plat biasanya akan membelah dan merusak bamboo kecuali jika dibor terlebih dahulu sebelum di paku. Alat sambung yang cocok untuk struktur bambu adalah diikat dengan tali berbagai macam bentuk.

Jenis sambungan bambu ada berbagai macam yang dapat dilihat pada Gambar 6, antara lain:
a) Purus
b) Purus berganda
c) Potongan
d) Potongan gigi
e) Potongan berbentuk baji
f) Lidah
g) Tembusan dengan pasak
h) Pasak wedokan dengan baji lanang
Bentuk - Bentuk sambungan bambu:
a) Sambungan memanjang - (Gambar 7)
b) Sambungan Siku - (Gambar 8)
c) Sambungan Silang - (Gambar 9)
d) Sambungan Penopang - (Gambar 10)
e) Sambungan Batang miring - (Gambar 11)
f) Berbagai pengikatan bambu dengan tali - (Gambar 12) 
a
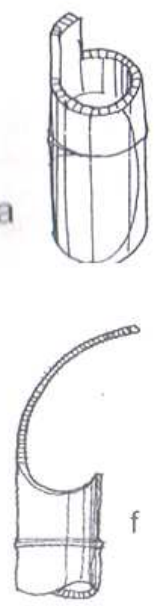

b

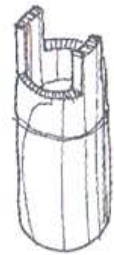

C

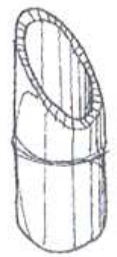

d

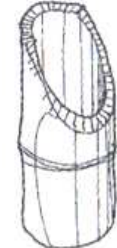

e
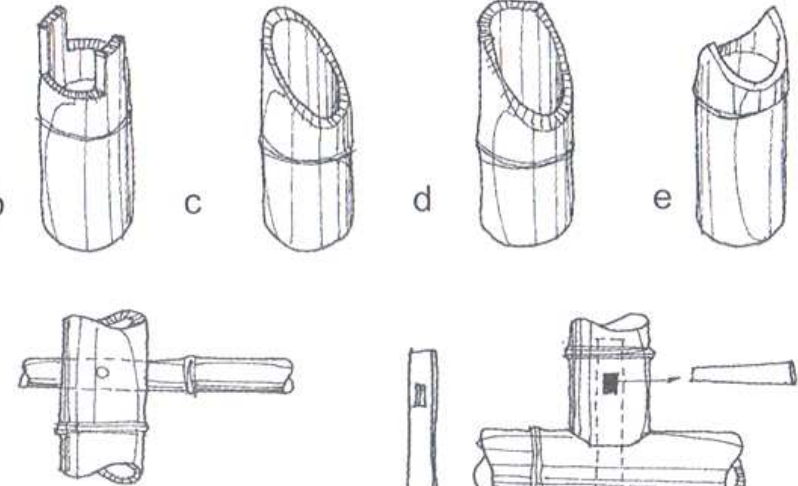

g
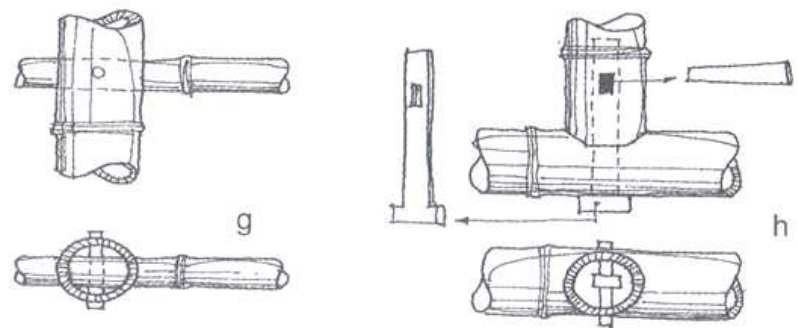

Gambar 6. Berbagai macam sambungan bambu biasa (Frick, 2004)

a

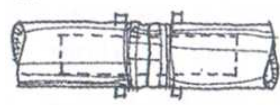

d

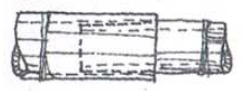

b

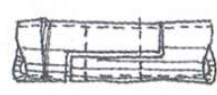

e

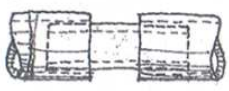

C

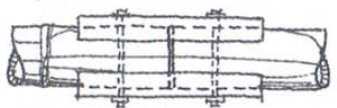

f

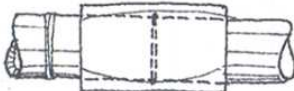

Gambar 7. Berbagai macam sambungan bambu memanjang (Frick, 2004)
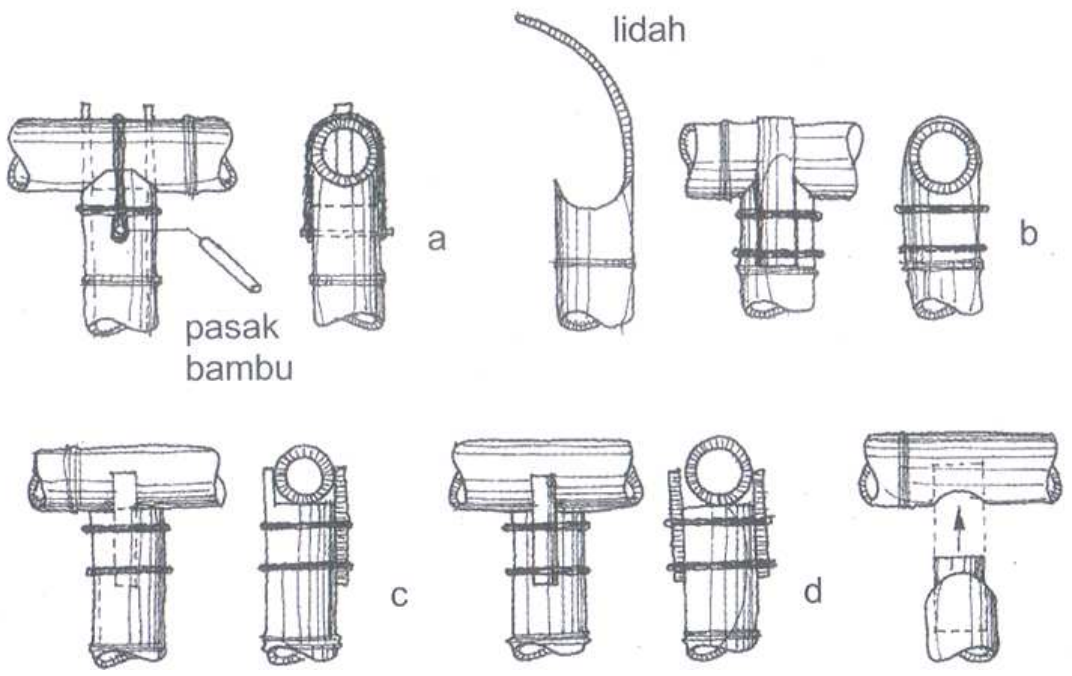

Gambar 8. Sambungan siku (Frick, 2004)
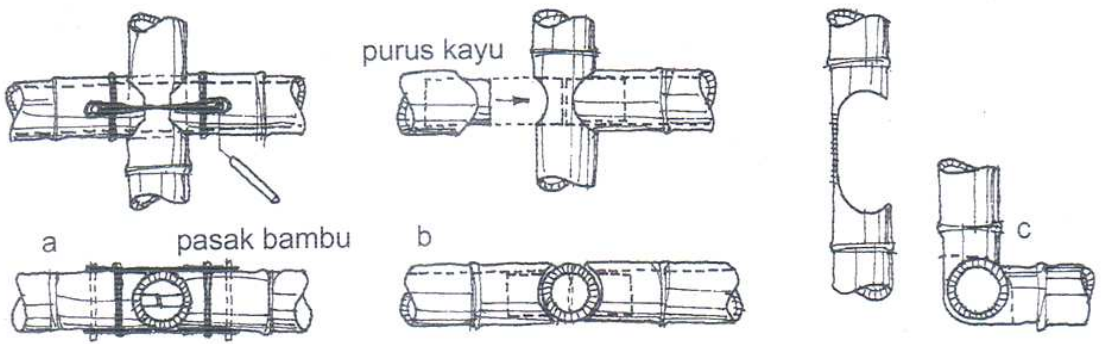

Gambar 9. Sambungan silang (Frick, 2004) 


\section{Kesimpulan}

1. Sambungan struktur rumus panggung yang terbuat dari berbagai jenis material harus bisa mampu menahan beban - beban yang bekerja dan memenuhi persyaratan yang diminta, sehingga struktur menjadi aman.

2. Sambungan baja dan beton, dengan menggunakan base plate dan angkur baut, memenuhi persyaratan perhitungan struktur dengan memasukkan ukuran dan tebal base plate, mutu beton dan baja yang digunakan.

3. Sistem sambungan struktur bambu dengan berbagai bentuk batang-batang bambu dengan menggunakan pasak, purus, tali temali lebih kokoh/kencang daripada menggunakan paku, karena paku menyebabkan batang bambu menjadi terbelah/pecah.

4. Sambungan kolom baja dengan struktur bambu dapat menggunakan pelat penyambung baja dan strip pelat baja berbentuk segitiga dengan diikat baut

5. Sambungan kolom Hidrolis, setelah disi terhadap geser blok, aman terhadap kemungkinan sobeknya pelat pipa galvanis.

\section{Ucapan Terimakasih}

Ucapan terimakasih ditujukan kepada Direktorat Riset dan Pengabdian Masyarakat, Direktorat Jenderal
Penguatan Riset dan Pengembangan, Kementerian Riset, Teknologi dan Pendidikan Tinggi Republik Indonesia yang telah mendanai penelitian ini selama 3 tahun.

Apresiasi disampaikan kepada Bapak Kepala Kelurahan Kemijen (Bp.Dwi Wiyana), Bapak Ketua RW 04 (Bapak Nur Timbul), Bapak Heriyanto dan Ibu Hanifah, warga RT 02/RW 04 Kelurahan Kemijen yang telah menyediakan lahannya untuk tempat penelitian ini dengan membangun rumah panggung hidrolis.

Penghargaan kami sampaikan kepada Rektor Universitas Katolik Soegijapranata (Prof. Dr. Ir. F. Ridwan Sanjaya SE, S.Kom, MS.IEC) dan ketua LPPM (Ibu Dr. Berta Bekti Retnawati M.Si.) beserta staff serta semua pihak yang telah membantu menyelesaikan penelitian ini.

\section{Referensi}

Dewobroto, W, (2002) Struktur Baja, Perilaku, Analisis dan Desain, AISC 1: 749-759

Frick, H, (2004) Ilmu Konstruksi Bangunan Bambu, Pengantar Konstruksi Bambu, Penerbit Kanisius: 2329

Listiati, Etty E, Tri Hesti Mulyani, B Tyas Susanti \& Widija Suseno Widjaja,(2018) Model Desain Rumah yang Adaptif Terhadap Rob di Kelurahan Kemijen Semarang.

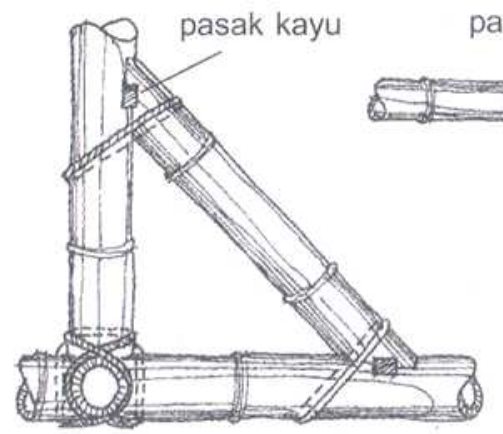

a) denah

pasak bambu

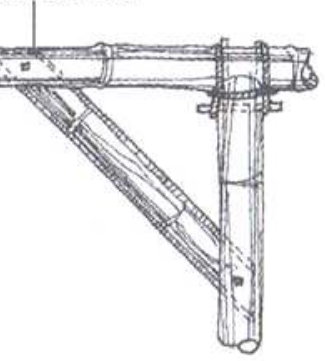

b) pandangan - potongan

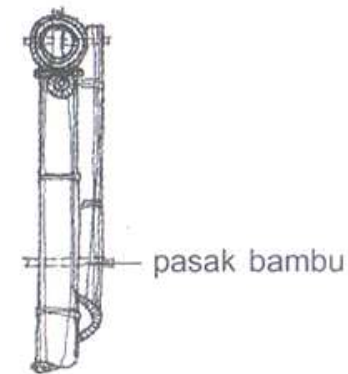

Gambar 10. Sambungan penopang (Frick, 2004)
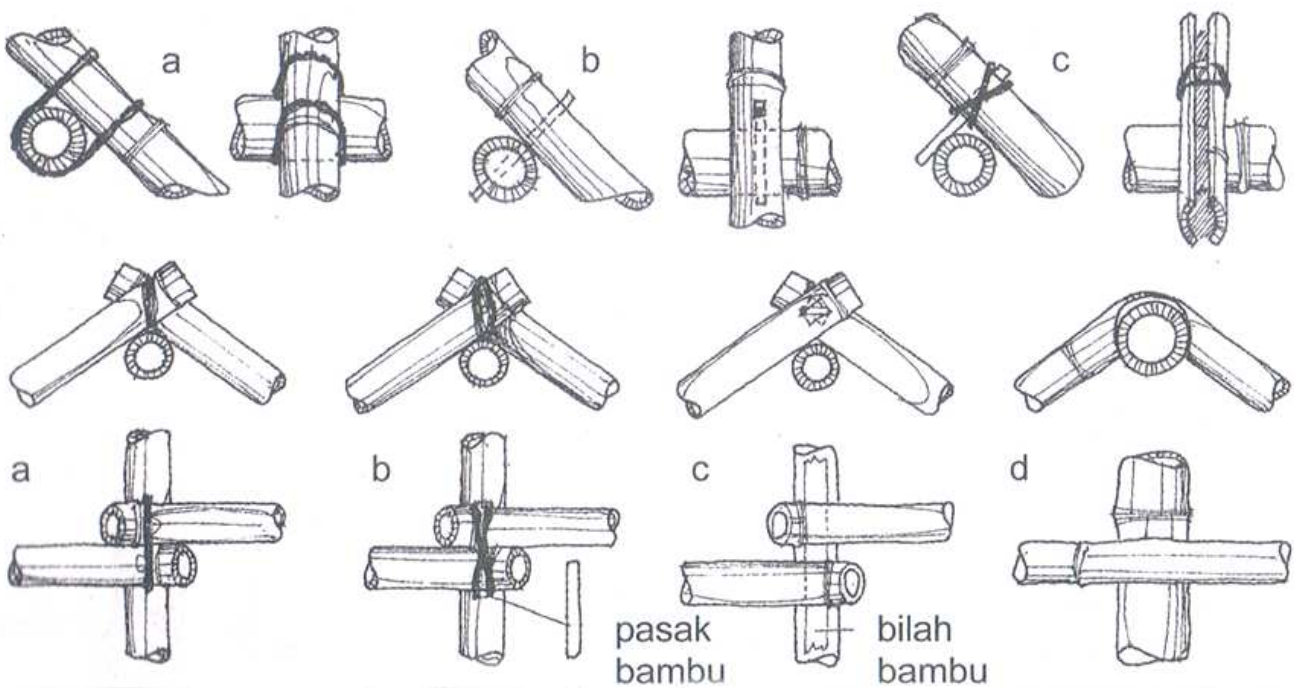

Gambar 11. Sambungan batang miring (Frick, 2004) 

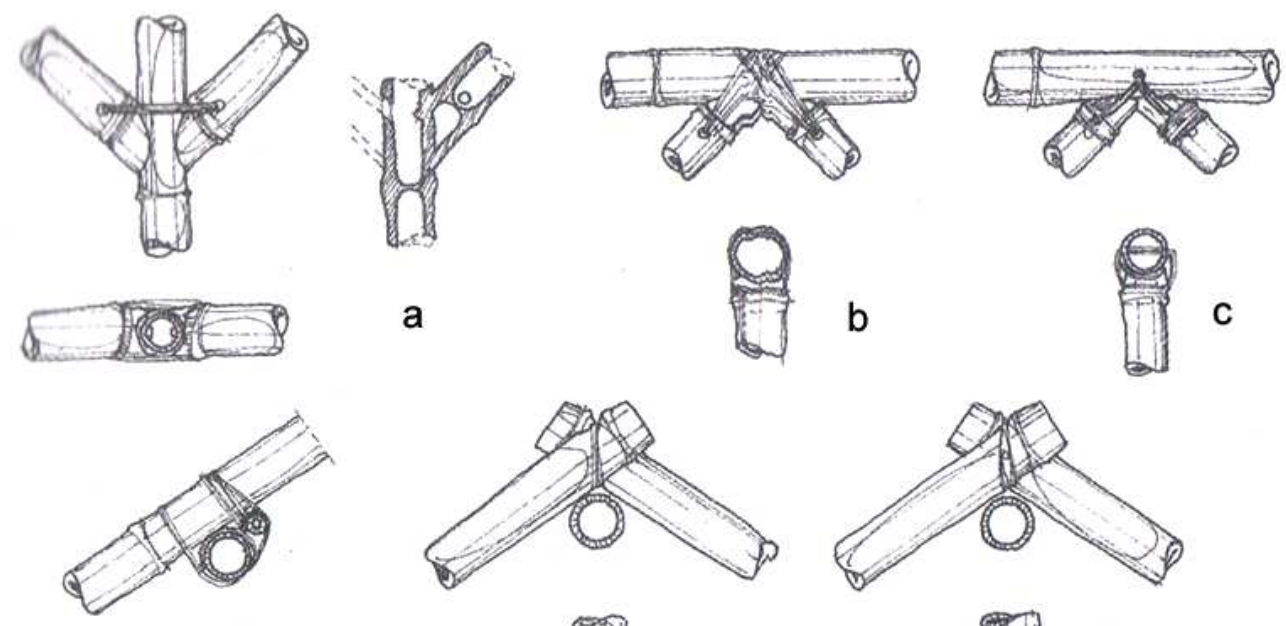

a
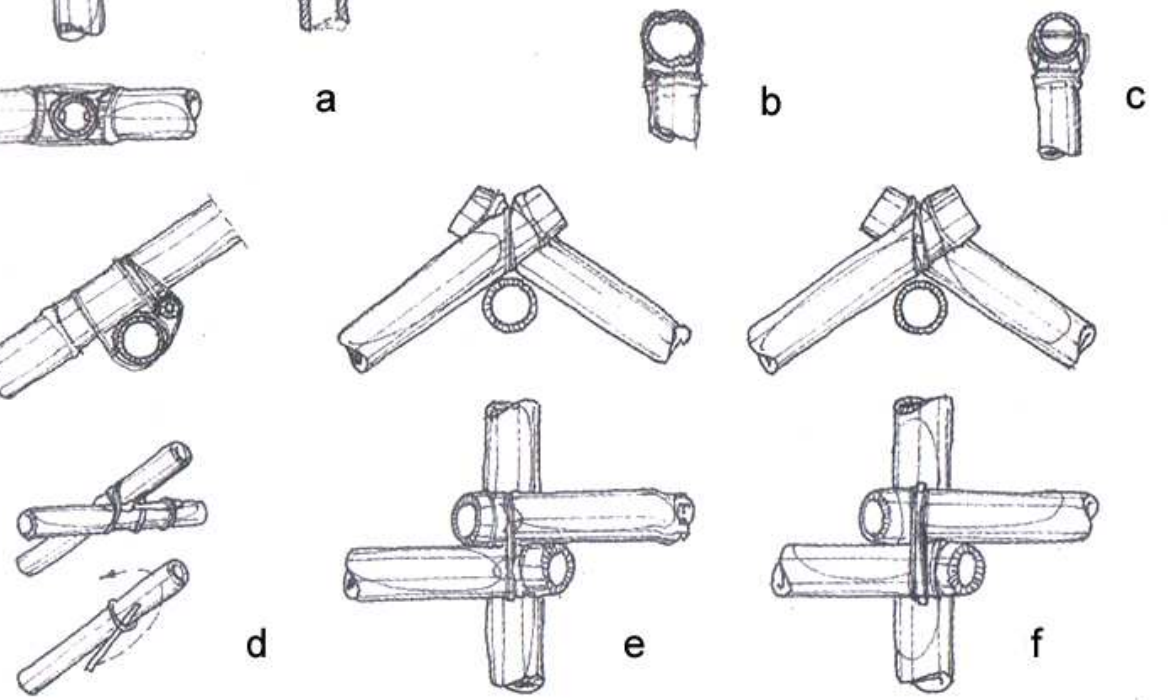

Gambar 12. Berbagai pengikatan bambu dengan tali 